Research Article

\title{
Investigation on Synthesis of Trimethylolpropane (TMP) Ester from Non-edible Oil
}

\author{
Nurazreen Shazwin binti Kamarudin ${ }^{1}$, Harumi Veny ${ }^{1, *}$, Nailah Fasihah Binti Sidek ${ }^{1}$, \\ Faisal Abnisa ${ }^{2}$, Rozana Azrina Sazali ${ }^{1}$, Noorhaliza Aziz ${ }^{3}$
}

${ }^{1}$ Faculty of Chemical Engineering, Universiti Teknologi MARA, 40450 Shah Alam, Selangor, Malaysia. ${ }^{2}$ Department of Chemical and Materials Engineering, Faculty of Engineering, King Abdulaziz University, Jeddah, Saudi Arabia.

${ }^{3}$ Faculty of Chemical Engineering, Pasir Gudang Campus, Johor Branch, Universiti Teknologi MARA, Johor, Malaysia.

Received: $4^{\text {th }}$ September 2020; Revised: $18^{\text {th }}$ October 2020; Accepted: $19^{\text {th }}$ October 2020; Available online: 9th November 2020; Published regularly: December 2020

\begin{abstract}
Trimethylolpropane (TMP) ester is an eco-friendly lubricant that fully biodegradable and known as bio lubricant. In this study, TMP ester was produced from waste cooking oil and rubber seed oil through a two-step synthesis approach. The reaction is two stages transesterifications, in which the waste cooking oil and the rubber seed oil were first transesterified with methanol to produce methyl ester, followed by transesterification with TMP using para-Toluenesulfonic acid ( $p$-TSA) as catalyst. Various effects of operating conditions were observed, such as reaction time, temperature and molar ratio of reactants. The TMP ester formation was determined based on the quantity of reactant conversion. The synthesized TMP ester was compared and characterized according to their properties. The results showed that the TMP ester from waste cooking oil (WCO) has shown better conversion compare to TMP ester from rubber seed oil (RSO), within a similar operating condition. The highest TMP ester conversion from WCO is $71 \%$, at temperature of $150{ }^{\circ} \mathrm{C}$ with molar ratio of FAME to TMP of 3:1 and catalyst amount of $2 \%(\mathrm{wt} / \mathrm{wt})$. In addition, these polyol based esters from WCO and RSO exhibit appropriate basic properties for viscosity when compare with requirement standard of lubricant ISO VG46. Copyright $($ C 2020 BCREC Group. All rights reserved
\end{abstract}

Keywords: biodiesel; rubber seed oil; waste cooking oil; biolubricant; transesterification; trimethylolpropane triester

How to Cite: Kamarudin, N.S., Veny, H., Sidek, N.F., Abnisa, F., Sazali, R.A., Aziz, N. (2020). Investigation on Synthesis of Trimethylolpropane (TMP) Ester from Non-edible Oil. Bulletin of Chemical Reaction Engineering \& Catalysis, 15(3), 808-817 (doi:10.9767/bcrec.15.3.8862.808-817)

Permalink/DOI: https://doi.org/10.9767/bcrec.15.3.8862.808-817

\section{Introduction}

Various application of lubricant has been giving rise on its demand and increase its price. However, lubricant is non-biodegradable and toxic when directly discharged into the environ-

\footnotetext{
* Corresponding Author.

Email: harumi2244@uitm.edu.my (H. Veny);

Telp: +60-035446511
}

ment and exposed with land, water, and air system [1]. Thus, the development of an environmentally friendly-based lubricant has become a greater interest by utilizing renewable resources. Recently, biolubricant derived from vegetable oil has shown great chances as a new generation of lubricants. Vegetable oil-based is preferred as the feedstock for biolubricant because it can be renewable, economical and non- 
toxic. The structure of the triglycerides in vegetable oil gives many advantages, such as: low volatility due to high molecular weight of triacylglycerol molecule, good boundary lubrication characteristics due to polar ester group, also high solubilizing power and high viscosity index for polar contaminants and additive molecules [2]. Vegetable oil can be classified into edible and non-edible oil. Edible oil can be consumed and is easily accessible, since it is an abundant source. Non-edible oil, on the other hand, cannot be consumed and have either little impact on global food cost or production because it can be either a waste or from plant that can be grown on nutrient-deficient land. Hence, the use of non-edible oil as feedstock for biolubricant may reduce the competition within the current agricultural resources [3]. There are few studies reported for biolubricant production from vegetable oil based such as palm oil, Jatropha curcas oil, rubber seed oil, Karanja oil, rapeseed oil, waste cooking oil and sesame oil [4-9].

However, the structure of vegetable oil may also affect its lubrication properties, such as: oxidation stability, hydrolytic instability, and low-temperature properties [5]. Therefore, the modification should be proposed to improve oil performance. There are two available syntheses for biolubricant production from vegetable oil, and both consist of two series of reactions.

The first reaction is a series of transesterification, where the triglyceride is synthesized with methanol to produce FAME using chemical catalysts or biocatalyst. The second step is carried on by reacting to the intermediate FAME formed from the first transesterification with TMP to produce TMP triester, also called biolubricant [10]. The two-consecutive series of transesterification process are written below:

$$
\begin{array}{ll}
\mathrm{TG}+3 \mathrm{M} & \leftrightarrow \mathrm{GLY}+3 \mathrm{FAME} \\
\mathrm{TMP}+3 \mathrm{FAME} & \leftrightarrow \mathrm{TMP} \text { Triester }+3 \mathrm{M}
\end{array}
$$

where TG is triglyceride, $\mathrm{M}$ is methanol, TMP is Trimethylolpropane, GLY is glycerol, respectively.

The second series of reactions are hydrolysis of triglyceride followed by esterification of fatty acid with TMP [11]. In hydrolysis, the reaction can speed up with catalysts, either chemical or biocatalyst, such as: alkali metal hydroxide (base catalyst), organic sulphonic acid (acid catalyst) and lipase [12,13]. Alkali catalyst gives higher reaction rate about 4000 times faster compare to acid catalyst at standard reaction temperature when using low quality feedstock
[12]. Immobilized enzyme from lipase is suitable biocatalyst for hydrolysis, as presence of water in reaction is sufficient for the lipase activity, Lipase is surface active enzyme that will bind with substrates at the oil-water interface thus oil and water can separate [13].

Commonly used polyol reactant in both reactions is neopentyl glycol (NPG), trimethylolpropane (TMP) and pentaerythritol (PET). Most of the synthetic esters biolubricant are manufactured based on branched polyols, especially neo-pentyl glycol (NPG), trimethylolpropane (TMP) and pentaerythritol (PE) [14]. These type of bio-lubricant have been accepted broadly as the bio-lubricant with better performance, by replacing glycerol with polyols [15]. Nevertheless, among the three polyols, TMP is considered more environmentally friendly, as it has relatively low melting point and moderate price [15]. In this study, TMP ester was synthesized through two series of transesterification from waste cooking oil oil (WCO) and rubber seed oil (RSO). The waste cooking oil was selected, because it has low in price when compared to RBD vegetable oils and its usage can reduce the waste deposition $[10,16]$. Rubber seed oil (RSO) is also nonedible oil that is considered as waste which contain of glycoside and not suitable for humans [3]. Furthermore, TMP is chosen compared to other polyols, because it has been widely used to produce environmental lubricants, cheaper in price, and has low melting points [17]. Synthesis of polyol based esters can be produced either from fatty acid or fatty acid methyl ester, using catalysts from acid, base or enzyme. Both feedstocks used in this study contains a high amount of free fatty acids (FFA), thus an acid catalyst is more suitable for the reaction. Because acid catalysts, such as: sulfonic, sulphuric acids, hydrochloric acids and phosphoric acids, demonstrates no measurable susceptibility to FFA. A previous study by Kamalakar et al. reported transesterification reaction of rubber seed oil using an acid catalyst, such as toluene-4-sulfonic acid, has obtained high yield in the range of 91-96.5\% [6]. Thus, this study follows to perform transesterification reaction catalyzed by $p$-TSA.

In this research, TMP ester was produced from two different based feedstocks of methyl ester which were synthetically derived from Waste cooking oil (WCOME) and Rubber seed Oil (RSOME). These Methyl esters (FAME) undergone transesterification reaction with TMP to produce TMP ester or biolubricant. Various operating conditions to produce high conver- 
sion of TMP esters were observed, such as temperatures, reactant molar ratios and reaction time. The biolubricant produced from both feedstocks are compared. The properties of biolubricant are then compared with standard lubricant ISO VG46. The result from this study is expected to be an alternative for producing more environmentally and sustainable lubricant.

\section{Materials and Methods}

\subsection{Materials}

Waste cooking oil methyl ester and rubber seed oil methyl ester were previously obtained from transesterification with methanol. 2Ethyl-2-(hydroxymethyl)-1,3-propanediol (TMP) $(\geq 99 \%)$ and Toluene-4-sulfonic acid monohydrate ( $p$-TSA) (99\%) were obtained from Merck, Malaysia. Other solvents, such as: hexane (analytical grade) was used directly without purification.

\subsection{Synthesis of Biolubricant}

Figure 1 displays the experimental setup for the biolubricant production via transesterification reaction. The reaction occurs in the threenecked round bottom flask, attached with the

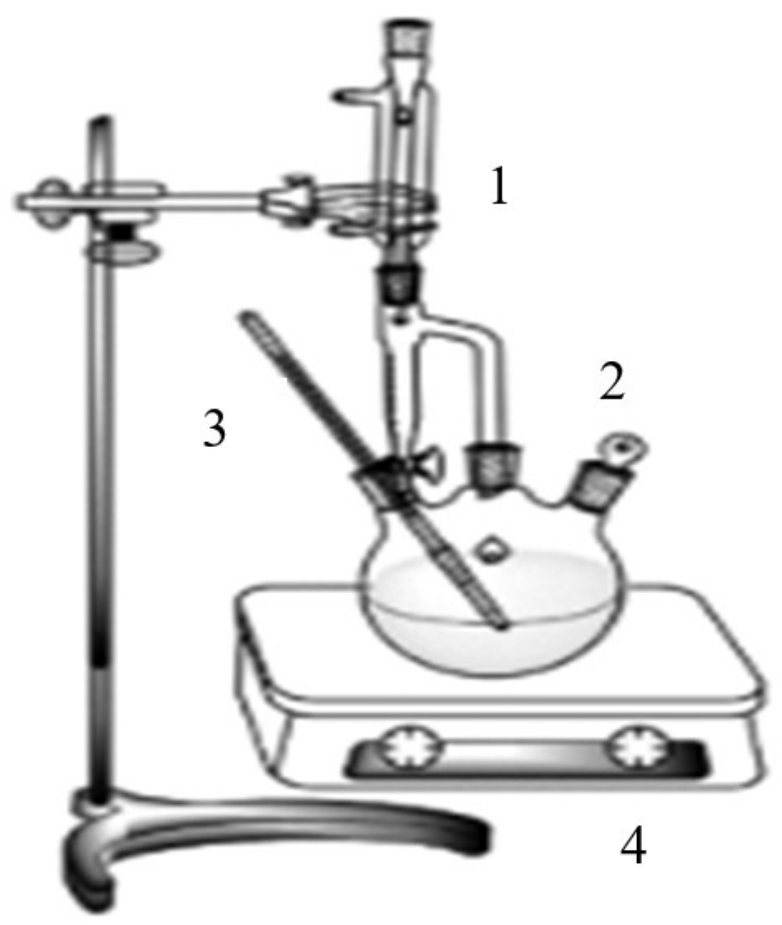

Figure 1. Experimental setup for TMP ester through double transesterification reaction [17]; (1) Condenser, (2) Three Neck Flask, (3) Thermometer, (4) Stirring Hotplate reflux condenser, a thermometer, and a sampling port. The transesterification reaction between the reactant of FAME and TMP was carried out by initially heated the TMP at $60{ }^{\circ} \mathrm{C}$ with continuous stirring. This temperature was maintained for about 15 minutes to remove moisture. The FAME was then poured at a known amount of molar ratio. The reaction was then proceeded according to the set temperature. After the desired temperature has been reached, $p$-TSA as a catalyst was added into the reaction. The sampling was the taken for every one hour and then it was purified by centrifugation. The formation of TMP ester or biolubricant is defined as conversion of biolubricant based on reduction of reactants (FAME), as shown below:

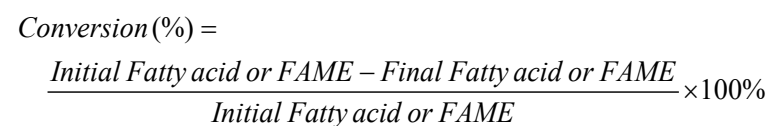

\subsection{Analysis of FAME}

The composition of FAME was determined using a GC-MS. GC-MS is the technique of analysis which developed to separate the sample according to the molecular mass and resulting from the data composition [18]. In this study, the composition of fatty acid present in the product from transesterification of FAME and TMP were analyzed with GC-MS. The GCMS used in this analysis is the combination of Varian 450-Gas Chromatograph with Varian 240-Mass Spectrometer Ion Trap. The column used was DB wax with $30 \mathrm{~m}$ long, with 0.25 $\mathrm{mm}$ i.d. and $0.25 \mu \mathrm{m}$ film thickness. The helium used as carrier gas at the head pressure of $0.55 \mathrm{~atm}$ and a split injection system at ratio 50:1. The inlet temperature was $250^{\circ} \mathrm{C}$ and the detector temperature was $280^{\circ} \mathrm{C}$. The prepared sample for $1 \mathrm{~mL}$ each was injected into the GC system. Confirmation of ester functional group in the synthesized biolubricant was also then identified FTIR.

\subsection{Analysis of Biolubricant Properties}

Basic properties of biolubricant were characterized based on the American Society for testing and material (ASTM) methods. The properties being investigated were cloud point, pour point, specific gravity and viscosity. These properties were carried out to observe the potential of lubricant characteristics. 


\subsubsection{Cloud point (ASTM D97)}

Cloud point can be defined as the minimum temperature where the sample becomes clouded when wax crystals are started to form. Cloud point was analyzed by using Cloud and Pour Point Apparatus. An amount of biolubricant sample was poured into a graduated jar until the level was marked with a line. The jar was closed tightly with a cork and was placed in the cooling bath. The sample was chilled until it is noted to become clouded at the bottom of the jar. The temperature at this point happen was recorded. The measurements were taken with every decrement of $2{ }^{\circ} \mathrm{C}$.

\subsubsection{Pour point (ASTM D97)}

Pour point is used to determine the flow properties of the fluid. A similar procedure to measure the cloud point was taken, however further chilling was continued until the biolubricant sample ceases to flow. The observation of sample flow was made by tilting the jar horizontally for 5 seconds and the temperature at which the sample shows no longer movement was recorded.

\subsubsection{Specific gravity (ASTM D941-55)}

Specific gravity is the ratio of the density of the used lubricating oil to the density of the equal volume of water. This was measured by using a hydrometer. The property was observed, and the value was recorded.

\subsubsection{Viscosity (ASTM D445)}

Viscosity was analyzed by using an Automated Micro Viscometer (AMVn). The capillary block of the clean viscometer was filled with the biolubricant sample while immersed in a

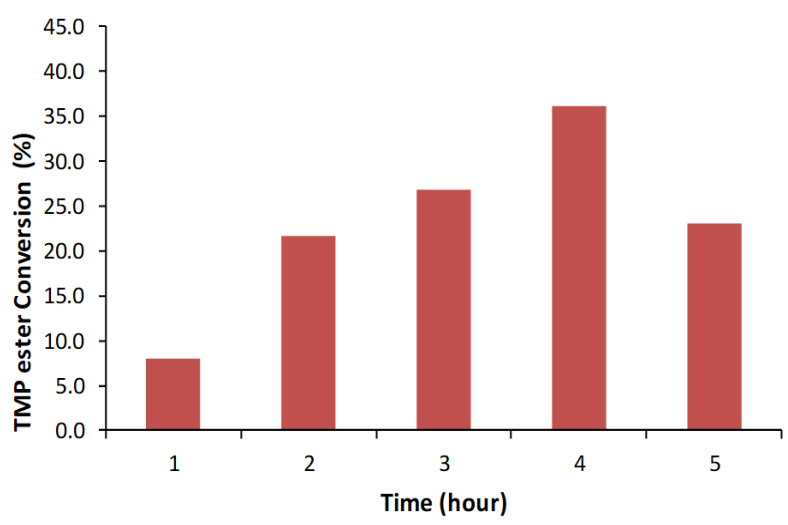

Figure 2. Effect of reaction time based on conversion of biolubricant in transesterification of WCOME using $p$-TSA as catalyst. thermostat. The temperature was set at $40{ }^{\circ} \mathrm{C}$ and the result was tabulated.

\section{Results and Discussion}

The synthesize of biolubricant from WCOME and RSOME were studied over the effects of reaction time, temperature and molar ratio of FAME to TMP. Throughout this study, the biolubricant was analyzed based on the conversion of reactant (FAME) into the product. The conversion of FAME to biolubricant was verified with GC-MS and FTIR. The synthesized product was characterized using ASTM standard by comparing with the standard lubricant.

\subsection{Preliminary Study on Reaction Time for} Transesterification of WCOME based Biolubricant

Determination of optimum reaction time for biolubricant production was obtained by carried out a preliminary study of transesterification between WCOME and TMP. The transesterification reaction conditions were as follows: temperature $140{ }^{\circ} \mathrm{C}, 3: 1$ ratio of WCOME to TMP with $2 \mathrm{wt} \%$ of $p$-TSA as the catalyst. The molar ratio used in the reversible reaction is theoretically created from the general transesterification reaction of FAME and TMP as written in equation 2 . The stoichiometric ratio for the forward reaction requires 3 moles of FAME and 1 mole of TMP. Figure 2 shows the effect of FAME conversion versus reaction time in the transesterification reaction. The major constituent of FAME which is hexadecenoic acid methyl ester was investigated based on the sample taken at every one (1) hour interval. The reaction time was varied from 0 to 5 hours.

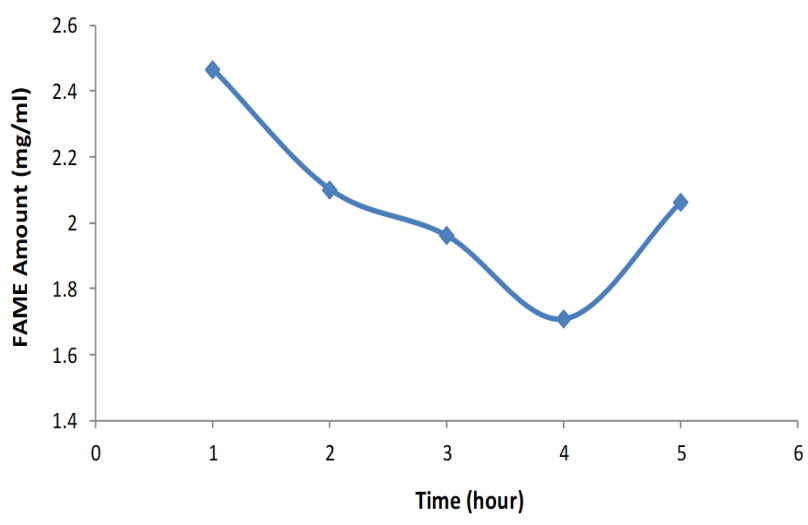

Figure 3. Time profile in transesterification of WCOME based on FAME amount using $p$-TSA as catalyst. 


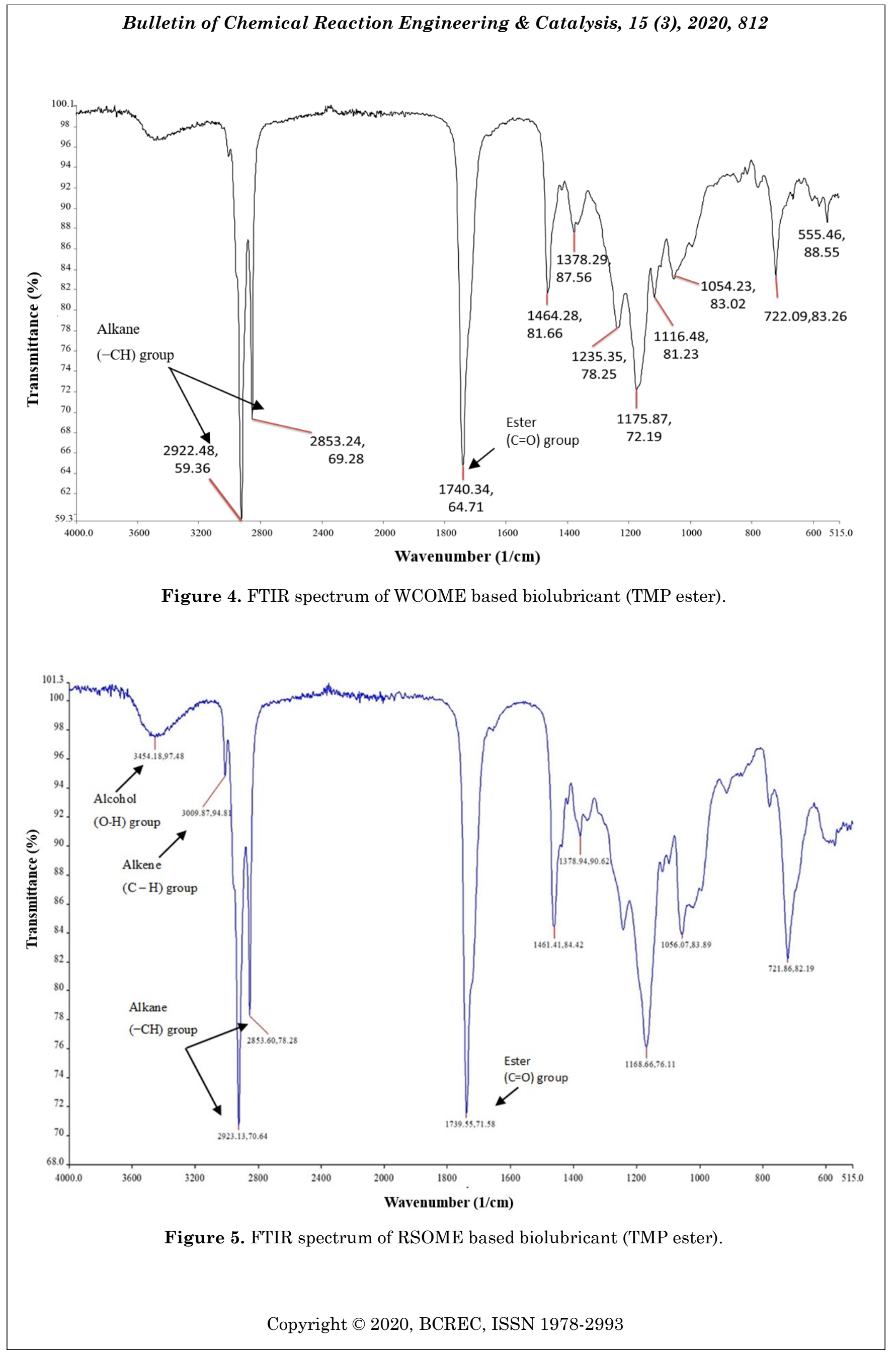


As can be seen from Figure 2, the conversion of FAME increased obviously as the reaction time increased from 0 to 4 hours. The conversion of FAME at 4 hours reaction time is the highest which is up to $36 \%$. Further increase of reaction time to 5 hours led to an adverse impact on FAME conversion, where the conversion decreased to $23 \%$. This is most probably because the reaction has completed at 4 hours and further reaction time may lead to reverse of the product into reactant. Additionally, according to Wang et al. result, the increasing reaction time will lead to higher usage in terms of energy and time [1]. The result from this study is used to describe reaction profile based on reduction of FAME amount as seen in Figure 3.

Figure 3 shows that FAME amount is still high at the beginning of the experiment, which is $2.47 \mathrm{mg} / \mathrm{mL}$ after 1 hour of reaction. Afterward, FAME amount starts to decrease until 4 hours of reaction. The amount of FAME was decreasing until only $1.71 \mathrm{mg} / \mathrm{mL}$ was left. However, extending reaction time after 4 hours made the FAME a mount started to increase to $2.06 \mathrm{mg} / \mathrm{mL}$ at 5 hours. This is most probably because of reversible reaction as explained earlier in Figure 2. Thus, it can be concluded that 4 hours was an optimum reaction time for further study in transesterification of WCOME and RSOME with TMP.

\subsection{FTIR Analysis of Biolubricant}

The functional group found in the WCOME based biolubricant was diagnosed by the infrared spectrum (FTIR). The conversion of FAME to TMP based ester obtained from transesterification between TMP and WCOME can be confirmed through the peak appearance of ester

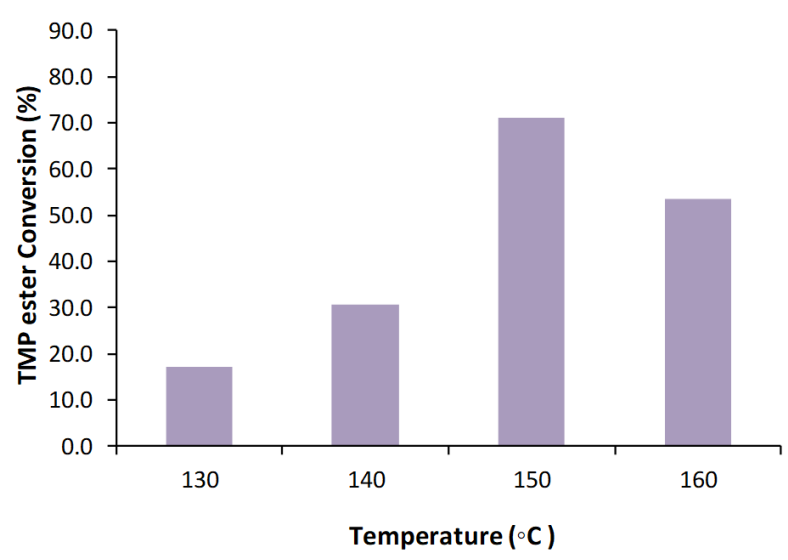

Figure 6. Effects of temperature on conversion in transesterification of WCOME using $p$-TSA as a catalyst. functional group at $1740.34 \mathrm{~cm}^{-1}$. A similar trend was obtained from the TMP ester of Jatropha oil-based [19]. A distinct peak also can be observed from the spectrum at wavenumber between 2800 to $3000 \mathrm{~cm}^{-1}$ resulting from $-\mathrm{CH}_{3}$ stretching vibration and $1464 \mathrm{~cm}^{-1}$ indicates $-\mathrm{CH}$ bending, the existence of alkane group [20].

The formation of TMP triester is from the intermediate of monoester and diester. If hydroxyl groups were partially esterified, monoester and diester will be formed. Triester, on the other hand, will be formed, when its hydroxyl groups were fully esterified [4]. The FTIR spectra for WCMOE based biolubricant shows in Figure 4. The hydroxyl $(\mathrm{O}-\mathrm{H})$ functional group is insignificant in WCOME spectra, as it is exhibited weaker IR absorbances compared to other groups. It shows that TMP has successfully reacted with FAME to produce TMP triester. Similar result has been reported by Musa et al. where the spectrum represents insignificant peak of hydroxyl group at a range of 3200-3600 $\mathrm{cm}^{-1}$ [21]. According to Sanni et al. result, no specific bond in the molecule may exist in the area without peaks, because it represents no photons are being absorbed in that frequency [22]. Different IR spectra for Hydroxyl functional group was obtained with RSOME based TMP ester as shown in Figure 5 . The $\mathrm{O}-\mathrm{H}$ functional group is quite clear at wavelength $3454 \mathrm{~cm}^{-1}$ for RSOME based TMP ester.

3.3 The Effect of Temperature on the Transesterification Reaction of WCOME

Reaction temperature gives a significant effect on most of the chemical reactions including transesterification. This research observed the effect of reaction temperature on the synthesis of WCOME based biolubricant by experimenting $130,140,150$ and $160{ }^{\circ} \mathrm{C}$ for 4 hours. The other reaction conditions were fixed in this series of experiments at 3:1 ratio of FAME to TMP and $2 \mathrm{wt} \% p$-TSA as a catalyst. Figure 6 illustrates the influence of reaction temperature towards the conversion of FAME. The highest amount of FAME converted into TMPE ester is about $71 \%$ at the temperature of 150 ${ }^{\circ} \mathrm{C}$. Comparable study from Panchal et al. also showed that conducting the reaction at high temperature above $100{ }^{\circ} \mathrm{C}$ may obtained higher yield, as it prolonged reaction time more than 3 hours [23].

In Figure 6, the lowest conversion is achieved at temperature $130{ }^{\circ} \mathrm{C}$. This can be due to the low reactant mobility in which ends 
up in a low reaction rate [24]. Reactions at low temperatures cause a slower rate because the reacting particles have less kinetic energy for product formation [25]. Since the synthesis of TMP triester is an endothermic reaction, it is a plus point to conduct the reaction at high temperature, but the temperature must not be too high [1]. The result obtained in this study proved that reaction at higher temperatures than the optimum, would give low conversion. This may also be contributed from vaporization of reactant volatile substance as well as enhancing the occurrence of a reverse reaction. Therefore, it is sufficient to operate the reaction at $150{ }^{\circ} \mathrm{C}$ for the optimum temperature of the transesterification of WCOME with TMP.

\subsection{Composition of WCOME based Biolubricant}

The chromatogram of FAME from WCOME based biolubricant was determined by using GC-MS. The GC-MS chromatogram peaks refer to the number of carbon contained in the sample product. The peak component in the chromatogram was identified by comparing it with the standard from the previous study [26].

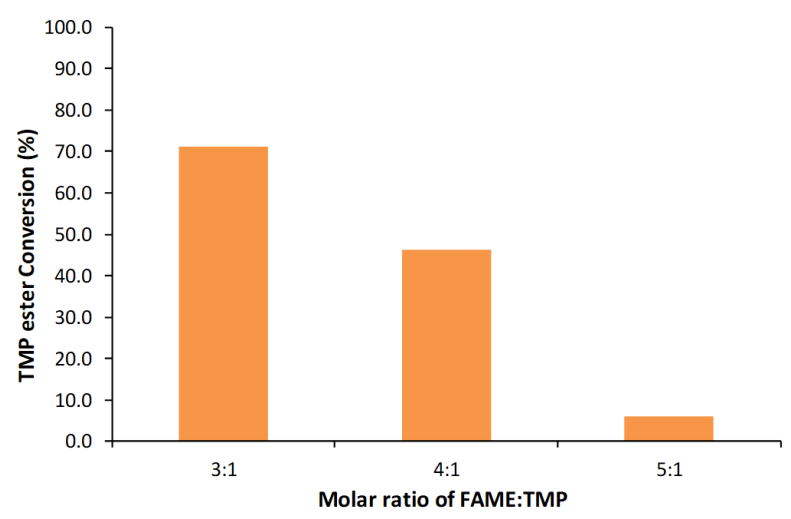

Figure 7. Effects of molar ratio of FAME:TMP on conversion in transesterification of WCOME using $p$-TSA as catalyst.
The percentage composition of $\mathrm{ME}$ in the production of biolubricant from WCOME based is tabulated in Table 1. The finding shows that saturated methyl esters were the major component in the synthesized biolubricant. Highest composition of methyl ester consists of methyl palmitate (52.52\%) followed by methyl (7Z)hexedecenoate (42.06\%), methyl stearate $(4.58 \%)$, and methyl tridecanoate (0.83\%). Overall, biolubricant synthesized from WCOME produced high saturated FAME at a mass fraction of $57.93 \%$ compare to unsaturated FAME wit mass fraction of $42.06 \%$. This is promising, because high saturation content in the biolubricant product will lead to higher resistance towards oxidative-thermal treatment [19]. On top of that, a high degree of saturated FAME also could develop a lubricant with high biodegradability and good low-temperature performance [27].

3.5 The Effect of Molar Ratio on the Transesterification Reaction of WCOME

Based on the general transesterification reaction, 3 moles of FAME are required to initiate a forward reaction with 1 mole of TMP, as shown below:

$$
3 \mathrm{WCOME}+\mathrm{TMP} \leftrightarrow \mathrm{TMPTE}+3 \mathrm{M}
$$

Transesterification is a reversible reaction and is accomplished by mixing the reactants of FAME and TMP. The synthesis of biolubricant from transesterification with presence of catalyst involves three phases of reactions. Initially, TMP monoesters (TMPME) is produced and it will be converted to form intermediates of TMP diesters (TMPDE) and finally become the final product, TMP triester (TMPTE).

Investigations on the effect of molar ratio of FAME to TMP for the synthesis of WCOME based biolubricant were varied at three different ratios which are 3:1, 4:1 and 5:1. Other op-

Table 1. The percentage composition of FAME in WCO based biolubricant.

\begin{tabular}{llc}
\hline FAME name & Common name & \multicolumn{2}{c}{ Percentage of total mass } \\
\hline Saturated FAME & & 0.83 \\
Tridecanoic acid methyl ester (C13:0) & Methyl tridecanoate & 52.52 \\
Hexadecanoic acid methyl ester (C16:0) & Methyl palmitate & 4.58 \\
Octadecanoic acid methyl ester (C18:0) & Methyl stearate & 42.06 \\
Unsaturated FAME & & 4 - \\
7Z-Hexadecenoic acid methyl ester (C16:1) & Methyl (7Z)-hexadecenoate & \\
\hline
\end{tabular}


erating conditions were kept constant throughout the experiment, such as: temperature 150 ${ }^{\circ} \mathrm{C}, 4 \mathrm{~h}$ reaction time and $2 \%(\mathrm{wt} / \mathrm{wt})$ of $p$-TSA as catalyst. Figure 7 describes the result achieved in percent conversion of FAME versus molar ratio of FAME to TMP. From Figure 7, it could be observed that $3: 1$ molar ratio possesses the highest conversion of $71 \%, 4: 1$ ratio at $46 \%$ conversion followed by $5 \%$ conversion occurred for 5:1 ratio. Thus, the optimum molar ratio for this study was at stoichiometric molar ratio of $3: 1$.

On account of the stoichiometric reaction, the production of biolubricant can be much better accomplished by experimenting with a higher molar ratio of reactants to enhance reaction completion [5]. However, in our study, increasing molar ratio of FAME to TMP above its stoichiometric molar ratio, decreased the conversion of reactant to biolubricant. This occurrence may be because higher content of FAME in the reaction, promoting the dilution of TMP concentration in the system and decreasing the collision probability of the nucleophilic particle [17]. Moreover, the previous study by Wang et al. stated that more energy will be needed to be recovered for excess amount of unreacted FAME [1]. As the consequences, that is why the increase in molar ratio of FAME:TMP had a negative impact on synthesizing biolubricant

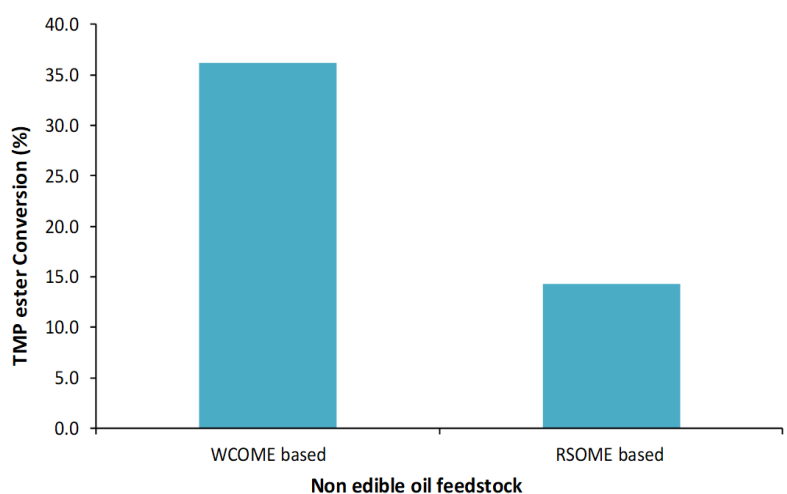

Figure 8. Comparison of conversion for biolubricant from Waste cooking oil (WCOME) and Rubber seed oil (RSOME) based in transesterification using $p$-TSA as a catalyst. based on the FAME conversion to the final product.

3.6 Comparative Study on Various Based Methyl Esters for Biolubricant Synthesis

The comparison of biolubricant from WCOME and RSOME based were studied at stoichiometric molar ratio of FAME to TMP $3: 1,4$ hours reaction time and $2 \%(\mathrm{wt} / \mathrm{wt})$ of $p$ TSA as catalyst. Figure 8 conveys the comparative study of FAME conversion on both feedstock. It is found that the conversion of RSOME based is much lower than WCOME, although reaction was not carried out at optimum temperature. During the experiment with RSOME, it was seen that the sample tends to be sludgy and viscous. The biolubricant from WCOME has conversion of $36 \%$, whereas conversion of RSOME based is $14 \%$. Thus increasing temperature for comparison purposes is not effective and efficient, because a higher reaction temperature could damage the appearance of the biolubricant and preventing a better yield of biolubricant [28].

\subsection{Properties of Biolubricant}

The properties of synthesized biolubricant were evaluated based on ASTM methods. The WCOME and RSOME based biolubricant was compared to an industrial lubricant ISO VG46. The ISO VG46 is a grade lubricant which normally use for light gear applications, crankcase and hydraulic fluid [18]. The overall result was tabulated in Table 2.

Viscosity is one of the important criteria to look for when selecting a lubricant. In this study, kinematic viscosity at $40{ }^{\circ} \mathrm{C}$ was measured by ASTM D445 method [29]. Viscosity of WCOME based biolubricant was found at 62.56 cSt and Viscosity of RSOME based biolubricant was at $40.2 \mathrm{cSt}$. Only biolubricant's viscosity from WCOME is within the requirement of ISO VG46 lubricant which is above 41.2 Similar result was reported by Kamalakar et al. [6].

Cloud point and Pour point were analyzed by ASTM D97 method and compared with the standard lubricant [30]. Cloud point from both

Table 2. Properties of Biolubricant.

\begin{tabular}{lccc}
\hline Specification & WCOME Biolubricant & RSOME Biolubricant & ISO VG46 [1] \\
\hline Specific gravity $(\mathrm{g} / \mathrm{mL})$ & 0.88 & 0.90 & N/A \\
Viscosity at $40{ }^{\circ} \mathrm{C}(\mathrm{cSt})$ & 62.56 & 40.2 & $>41.4$ \\
Cloud Point $\left({ }^{\circ} \mathrm{C}\right)$ & 14 & 2 & N/A \\
Pour Point $\left({ }^{\circ} \mathrm{C}\right)$ & 8 & -4 & -6 \\
\hline
\end{tabular}


WCOME and RSOME obtained higher values compared to study in from $\mathrm{Li}$ and Wang [31]. However, the values are not applicable for ISO VG46 lubricant standard. The pour point of WCOME and RSOME based biolubricant were not in the range of lubricant standard, which are $8{ }^{\circ} \mathrm{C}$ and $-4{ }^{\circ} \mathrm{C}$, respectively. Unlike current study, other reported study that derived biolubricant from WCOME shows a lower pour point at $-3{ }^{\circ} \mathrm{C}[32]$. Lower pour point was also obtained for RSOME based biolubricant which is $-6{ }^{\circ} \mathrm{C}$ [6]. This probably due to high level of saturation from palmitic content ( $52.52 \%$ ) that may remove the effect of cis-unsaturation in biolubricant [19]. According to Alang et al. result, a higher pour point increases thermal stability and can endure mechanical stress better than petroleum lubricants [33].

\section{Conclusions}

Trimethylolpropane (TMP) ester (biolubricant) has been successfully produced as alternatives lubricant from two different non-edible oil based, which are Waste cooking oil (WCO) and Rubber Seed Oil (RSO). The twosteps transesterification reaction was selected for the process, where WCO and RSO were first transesterified with methanol to form WCO methyl ester (WCOME) and RSO methyl ester (RSOME), followed by transesterification with Trimethylolpropane(TMP). The use of nonedible vegetable oil-based as the feedstock in this study can avoid impact on environment and food security's issues. Observation with various operating conditions have shown that TMP ester was best produced from Waste cooking oil. The biolubricant from WCOME was confirmed with Infra-Red spectra where strong formation of ester and alkene were detected without significant hydroxyl functional group. Comparison of biolubricant properties with lubricant standard of ISO VGA 46 depicts that only viscosities for both WCOME and RSOME based are meet the requirement. Thus, further study to improve the quality of biolubricant from Waste cooking oil and Rubber seed oil is recommended.

\section{Acknowledgement}

Authors would like to thanks to Institute of Quality and Knowledge Advancement (INQKA) Universiti Teknologi MARA (UiTM) for publication funding.

\section{References}

[1] Wang, E., Ma, X., Tang, S., Yan, R., Wang, Y., Riley, W.W., Reaney, M.J.T. (2014). Synthesis and oxidative stability of trimethylolpropane fatty acid triester as a biolubricant base oil from waste cooking oil. Biomass and Bioenergy, 66, 371-378.

[2] Soni, S., Agarwal, M. (2014). Lubricants from renewable energy sources - a review. Green Chem. Lett. Rev., 7(4), 359-382.

[3] McNutt, J., He, Q. (2016). Development of biolubricants from vegetable oils via chemical modification. J. Ind. Eng. Chem., 36, 1-12.

[4] Salih, N., Salimon, J., Jantan, F.N. (2013). Synthesis and characterization of palm kernel oil based trimethylolpropane ester. Asian J. Chem., 25(17), 9751-9754.

[5] Menkiti, M.C., Ocheje, O., Agu, C.M. (2017). Production of environmentally adapted lubricant base stock from Jatropha curcas specie seed oil. Int. J. Ind. Chem., 8(2), 133-144.

[6] Kamalakar, K., Rajak, A.K., Prasad, R.B.N., Karuna, M.S.L. (2013). Rubber seed oil-based biolubricant base stocks: A potential source for hydraulic oils. Ind. Crops Prod., 51, 249257.

[7] Sharma, U.C., Sachan, S., Trivedi, R.K. (2019). Viscous flow behaviour of karanja oil based biolubricant base oil. J. Oleo Sci., 67(1), 105-111.

[8] Wang, Y., Zhou, C., Zheng, G., Sun, Y. (2014). Synthesis and Optimization of Trimethylolpropane Rapeseed Oil Ester. Adv. Mater. Res., 1015, 610-614.

[9] Dodos, G.S., Zannikos, F., Lois, E. (2011). Utilization of Sesame Oil for the Production of Bio-based Fuels and Lubricants. 3rd Int. CEMEPE SECOTOX Conf., 1(1), 623-628.

[10] Salimon, J., Salih, N., Yousif, E. (2010), Biolubricants: Raw materials, chemical modifications and environmental benefits. Eur. J. Lipid Sci. Technol., 112, 519-530. DOI: 10.1002/ejlt.200900205

[11] Arbain, N.H., Salimon, J. (2011). The Effects of Various Acid Catalyst on the Esterification of Jatropha Curcas Oil based Trimethylolpropane Ester as Biolubricant Base Stock. Journal of Chemistry, 8, 789374. DOI: 10.1155/2011/789374.

[12] Eze, V.C., Phan, A.N., Harvey, A.P. (2018). Intensi fi ed one-step biodiesel production from high water and free fatty acid waste cooking oils. Fuel, 220, 567-574.

[13] Talukder, M.M.R., Wu, J.C., Chua, L.P.L. (2010). Conversion of waste cooking oil to biodiesel via enzymatic hydrolysis followed by 
chemical esterification. Energy \& Fuels, 24(3), 2016-2019.

[14] Umaru, M., Aris, M.I., Munnir, S.M., Aliyu, A.M., Aberuagba, F., Isaac, A.J. (2016). Statistical optimization of biolubricant production from Jatropha curcas oil using trimethylolpropane as a polyol. Proceedings of the World Congress on Engineering and Computer Science 2016, Vol II (WCECS 2016), October 19-21, 2016, San Francisco, USA, Page 1-6.

[15] Abd, H., Yunus, R., Rashid, U., Choong, T.S.Y., Al-Muhtaseb, A.H. (2012). Synthesis of palm oil-based trimethylolpropane ester as potential biolubricant: Chemical kinetics modeling. Chem. Eng. J., 200-202, 532-540.

[16] Karonis, D., Chilari, D. (2013). A Comparison Between Of Sodium Methoxide And Sodium Hydroxide Catalysts For Ethyl Esters Production. Proceedings of the 13th International Conference of Environmental Science and Technology, Athens, Greece, 5-7 September 2013, Page 1-8.

[17] Qiao, S., Shi, Y., Wang, X., Lin, Z., Jiang, Y. (2017). Synthesis of Biolubricant Trimethylolpropane Trioleate and Its Lubricant Base Oil Properties. Energy \& Fuels, 31, 7185-7190.

[18] Faiz, M., Gunam, M., Idaty, T., Ghazi, M., Idris, A. (2012). Kinetic study of jatropha biolubricant from transesterification of jatropha curcas oil with trimethylolpropane : Effects of temperature. Ind. Crop. Prod., 38, 87-92.

[19] Heikal, E.K., Elmelawy, M., Khalil, S.A., Elbasuny, N. (2017). Manufacturing of environment friendly biolubricants from vegetable oils. Egypt. J. Pet., 26, 53-59.

[20] Masood, H., Yunus, R., Choong, T.S.Y., Rashid, U., Taufiq, Y.H. (2012). Synthesis and characterization of calcium methoxide as heterogeneous catalyst for trimethylolpropane esters conversion reaction. Appl. Catal. A Gen., 425-426, 184-190.

[21] Musa, U., Mohammed, I.A., Sadiq, M.M., Aberuagba, F., Olurinde, A.O., Obamina, R. (2015). Synthesis and Characterization of Trimethylolpropane-Based Biolubricants from Castor Oil. Proceedings of the 45th Annual Conference of NSChE, 5-7 th Nov., 2015, Warri, Nigeria. Page 248 -253.

[22] Sanni, S.E., Emetere, E., Efeovbokhan, V.E., Udonne, J.D. (2017). Process Optimization of the Transesterification Processes of Palm Kernel and Soybean Oils for Lube Oil Synthesis. Int. J. Appl. Eng. Res., 12(14), 4113-4129.
[23] Panchal, T., Chauhan, D., Thomas, M., Patel, J. (2015). Bio-based grease A value added product from renewable resources. Ind. Crops Prod., 63, 48-52.

[24] Theam, K.L., Islam, A., Choo, Y.M., TaufiqYap, Y. H. (2015). Biodiesel from low cost palm stearin using metal doped methoxide solid catalyst. Ind. Crops Prod., 76, 281-289.

[25] Yunus, R., Idris, A. (2003). Preparation and Characterization of Trimethylolpropane Esters From Palm Kernel Oil Methyl Esters. J. Palm Oil Res., 15, 42-49.

[26] Yunus, R., Lye, O.T., Fakhru'l-Razi, A., Basri, S. (2002). A simple capillary column GC method for analysis of palm oil-based polyol esters. J. Am. Oil Chem. Soc., 79(11), 10751080.

[27] Nagendramma, P., Kaul, S. (2011). Development of ecofriendly/biodegradable lubricants: An overview. Renew. Sustain. Energy Rev., 16, 764-774.

[28] Chang, T.S., Masood, H., Yunus, R., Rashid, U., Choong, T.S.Y., Biak, D.R.A. (2012). Activity of calcium methoxide catalyst for synthesis of high oleic palm oil based trimethylolpropane triesters as lubricant base stock. Ind. Eng. Chem. Res., 51(15), 54385442 .

[29] ASTM International (2011). Standard Test Method for Kinematic Viscosity of Transparent and Opaque Liquids (and Calculation of Dynamic Viscosity).

[30] ASTM International (2013). Standard Test Method for Pour Point of Petroleum Products.

[31] Li, W., Wang, X. (2015). Bio-lubricants Derived from Waste Cooking Oil with Improved Oxidation Stability and Low-temperature Properties. J. Oleo Sci. J. Oleo Sci, 64(4), 367-374.

[32] Borugadda, V.B., Goud, V.V. (2016). Improved thermo-oxidative stability of structurally modified waste cooking oil methyl esters for bio-lubricant application. J. Clean. Prod., 112, 4515-4524.

[33] Alang, M.B., Ndikontar, M.K., Sani, Y.M., Ndifon, P.T. (2018). Synthesis and Characterisation of a Biolubricant from Cameroon Palm Kernel Seed Oil Using a Locally Produced Base Catalyst from Plantain Peelings. Green Sustain. Chem., 8, 275-287. 